\title{
Organic pollutants in groundwater: remediation by nanoscale iron particles
}

\author{
M. G. O. Souza, F. T. Silva \& J. F. Oliveira \\ Department of Materials and Metallurgical Engineering, COPPE, \\ Federal University of Rio de Janeiro, Brazil
}

\begin{abstract}
The utilization of zero-valent iron particles in the degradation of organic compounds was studied in the present work. The Orange 6 dye was selected as the organic contaminant and initial experiments have been carried out using 10 $\mu \mathrm{m}$ particles. The iron nanoparticles used in the degradation studies were produced in the laboratory. The main parameters evaluated in the experiments were the effect of $\mathrm{pH}$, the metallic iron concentration and contact time. The adsorption of the organic dye onto the quartz surface was studied by zeta potential measurements. Quartz is generally one of the main constituents of the aquifer walls. The organic dye increased the negative zeta potential of quartz particles. This interaction between quartz and the dye compound should be taken into consideration in the environmental application of the zero-valent iron technology. The studies on the degradation of the Orange 6 organic dye by nanoscale iron particles showed that $98 \%$ of the dye can be degraded within 30 minutes of contact. Due to the favorable transport of nanoparticles in porous media of the groundwater aquifers and the flexibility for in situ applications, this innovative technology seems to have great prospects in the remediation of water pollution by organic compounds.
\end{abstract}

Keywords: groundwater remediation, zero-valent iron, organic compounds.

\section{Introduction}

Groundwater pollution by organic chemicals has become a matter of great concern due to the large scale production of plastics, solvents and pesticides. Organic dyes are also an important class of environmental contaminant. Recent studies have demonstrated the potential importance of nanoscale iron particles as 
a new remediation technology (Lien and Zhang [1], Liu et al. [2]). The use of granular zero-valent iron in permeable reactive barriers has been previously investigated (Gillham and O'Hannesin [3], Matheson and Tratnyek [4] and Reynolds et al. [5]). More recently, an interesting approach was undertaken by Wadley et al. [6], who studied the use of granular iron mixed with bentonite, as a lubricant to facilitate injection, in the degradation of dense nonaqueous phase liquids.

Nanoscale iron particles and bimetallic (Pd-Fe, Pt-Fe) particles have been used in the remediation of pollution by chlorinated compounds (Elliot and Zhang [7], Liu et al. [2]). However, the efficient management of the problem still needs additional scientific information concerning the degradation of pollutant compounds and their behavior in the aquifer after contact with the iron nanoparticles. The presence of organic compounds in groundwater is generally a long lasting problem due to its resistance to the biodegradation treatment in the subsurface conditions.

The redox pair $\mathrm{Fe}^{0} / \mathrm{Fe}^{2+}$ presents an oxidation potential of $0,44 \mathrm{~V}$, which is high enough to reduce a great number of organic contaminants. The iron nanoparticles generally present a high reactivity due to their large surface area and also a high mobility when used in subsurface water treatment. They have been used both for in situ and ex situ treatment (Elliot and Zhang [7]). The technology of reactive nanoparticles is considered to present a much lower cost than the permeable reactive barriers technology based on granular particles as well as in relation to the traditional "pump and treat" processes.

A high percentage of the dye compounds used by the textile industry belong to the azocompounds group $(-\mathrm{N}=\mathrm{N}-)$, and they are known to interfere in the biologic cycles of the aquatic environment and oxygen content of the water. The remediation of contamination by dye compounds using zero-valent iron has been studied by Deng et al. [8]. These authors included also in their experiments the use of UV radiation. In the present work some details of the use of granular and nanoscale iron particles in the degradation of Orange 6 dye are were studied aiming at its application as a groundwater remediation process.

\section{Experimental}

The $10 \mu \mathrm{m}$ iron particles used in the experiments were supplied by MERCK and iron nanoparticles $(20 \mathrm{~nm})$ were synthesized in the laboratory according to the methodology developed by Sun et al. [9]. The particle size distribution of the iron nanoparticles was controlled by light scattering measurements in the Zetasizer-nano Series (Malvern) and also analysed by transmission electron microscopy (MET) in a Jeol JEM 2000 FX equipment.

The Tropaeolin colorant (Orange 6), $\left(\mathrm{C}_{12} \mathrm{H}_{9} \mathrm{~N}_{2} \mathrm{O}_{5} \mathrm{SNa}\right.$ ), supplied by SPECTRUM, was used as the organic pollutant. Its structural formula is presented in Figure 1.

The colorant solutions were prepared by using Milli-Q water and the $\mathrm{pH}$ was adjusted with $\mathrm{NaOH}$ and $\mathrm{HCl}$. The degradation experiments were carried out in assay tubes containing the colorant solution to which iron particles were added. 
The tubes were then placed under ultra-sound agitation for a short time of two minutes and then placed in an orbital shaker for a longer period of time. Following that, the samples taken were then placed in a centrifuge (CL3, Model OM 3750, Thermo IEC) for 3 minutes at $3000 \mathrm{rpm}$. The final colorant concentration was determined by molecular absorption spectrometry using UVVis equipment (Model 1601PC, Shimadzu Corporation) at the wavelength of 430 nm.

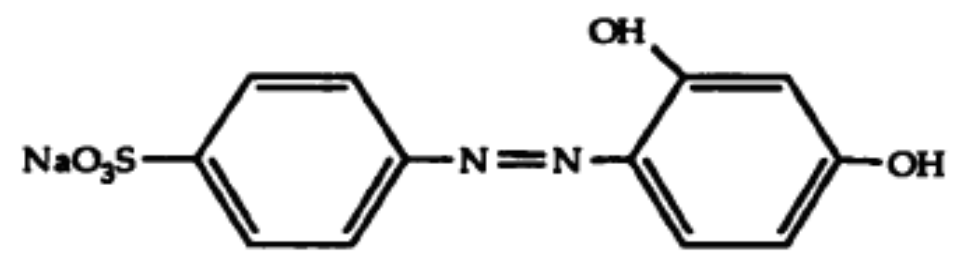

Figure 1: $\quad$ Structure of Tropaeolin O (Orange 6), the colorant commonly used in the textile industry and frequently discarded as a pollutant.

Zeta potential measurement were carried out aiming at studying the influence of the colorant Orange 6 on the surface properties of quartz, considering that this mineral is one of the main constituents of the underground aquifers rocks. For these experiments, equipment from Rank Brothers Ltd., UK (Model Mark IV) was used. The quartz suspensions were placed in contact with the Tropaeolin colorant solution at various concentrations at $\mathrm{pH}=6.0$.

\section{Results}

Figure 1 presents the size distribution of the iron particles synthesized by reduction of a $\mathrm{FeCl}_{3}(0,05 \mathrm{M})$ solution at $\mathrm{pH}=3.0$ and $10^{\circ} \mathrm{C}$, using $\mathrm{NaBH}_{4}(0.2 \mathrm{M})$. At this temperature the light scattering measurements showed a particle size range between 60 and 120nm. These results show that the iron particles synthesized in these conditions present a diameter around $78 \mathrm{~nm}$ and a grain size distribution quite homogeneous. However, the images obtained by transmission electron microscopy (Figure 2) showed that the average particles size is in fact around $20 \mathrm{~nm}$. It can be seen that the individual particles present a spherical shape and a clear tendency to agglomerate, what could explain the greater particle size observed by light scattering.

The degradation experiments showed that $0,2 \mathrm{~g}$ of the $10 \mu \mathrm{m}$ iron particles supplied by MERCK added to $100 \mathrm{~mL}$ of a 10ppm of the Orange 6 dye was almost completely degraded in 116 hours of contact.

The effect of using iron nanoparticles can be observed in Figure 4. Due to its much higher specific surface area, it can be seen that the iron nanoparticles produced a much higher degradation of the organic pollutant. These results show the importance of contact surface area between the metallic particles and the solution, as observed previously by Matheson and Tratnyek [4], and by Agrawal and Tratnyek [10]. 


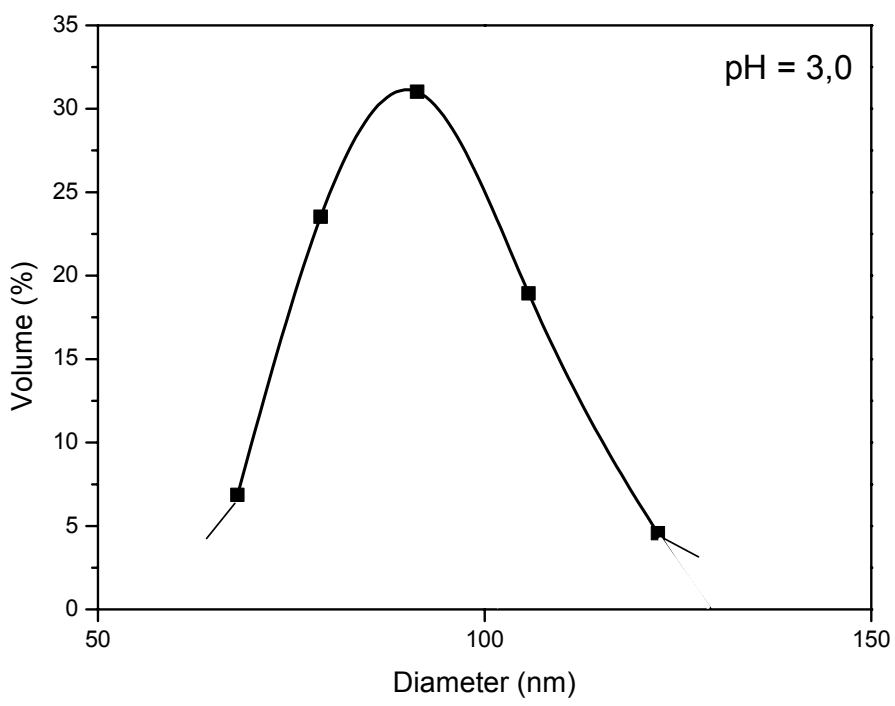

Figure 2: Grain size volumetric distribution obtained by light scattering of iron nanoparticles produced by the reduction of $\mathrm{FeCl}_{3}(0,05 \mathrm{M})$ with $\mathrm{NaBH}_{4}(0,2 \mathrm{M})$, at $\mathrm{pH}=3.0$ and temperature of $10^{\circ} \mathrm{C}$.

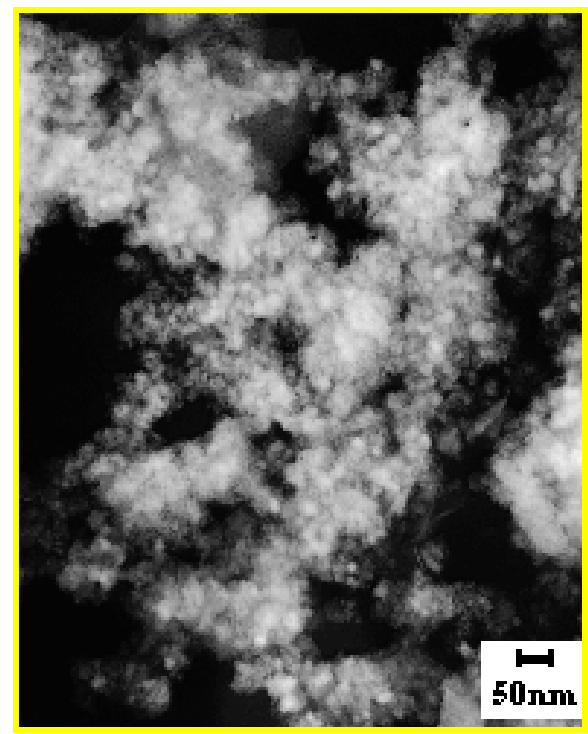

Figure 3: Transmission electron microscopy image of iron nanoparticles produced by ferric chloride reduction with $\mathrm{NaBH}_{4}$ at $\mathrm{pH}=3.0$ and $10^{\circ} \mathrm{C}$. 


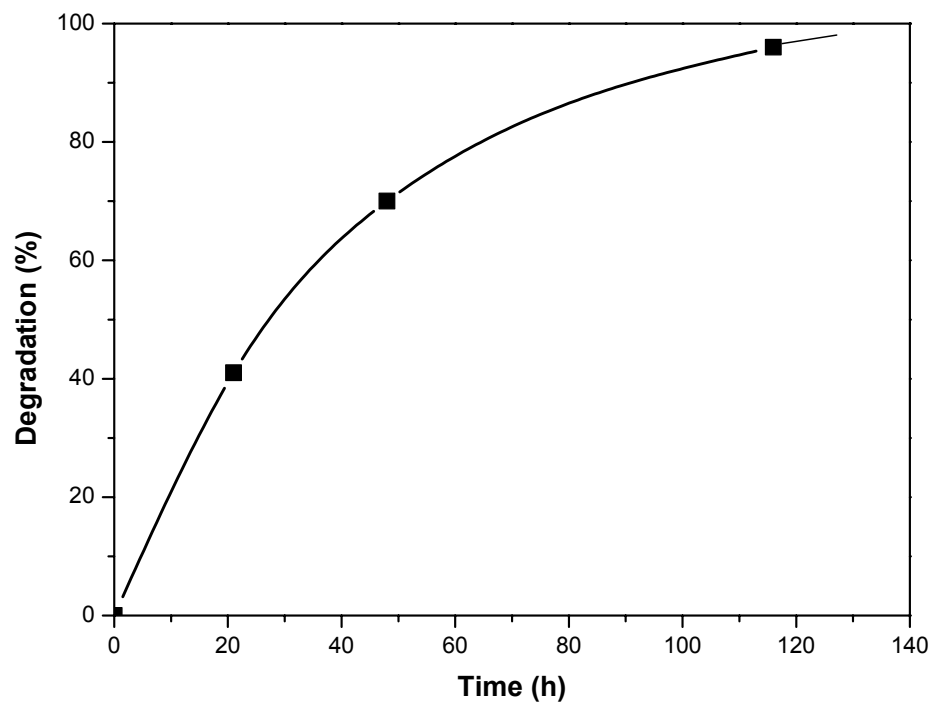

Figure 4: Degradation of the Orange 6 as a function of time after addition of $0,2 \mathrm{~g}$ of granular metallic iron $(10 \mu \mathrm{m})$ to $100 \mathrm{~mL}$ of the pollutant solution (10ppm), at $\mathrm{pH}=4.0$.

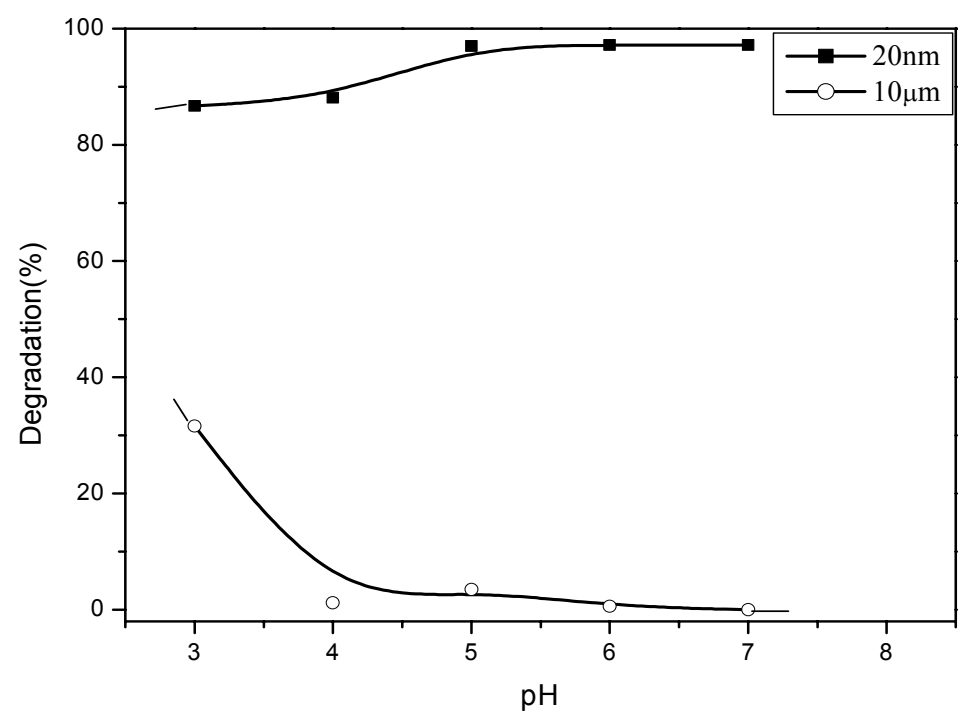

Figure 5: Degradation of the Orange 6 dye solution (5pm) by micrometric $(10 \mu \mathrm{m})$ and nanometric $(20 \mathrm{~nm})$ iron particles $(0.3 \mathrm{~g} / 100 \mathrm{~mL})$, after a contact time of 30 minutes, as a function of $\mathrm{pH}$. 


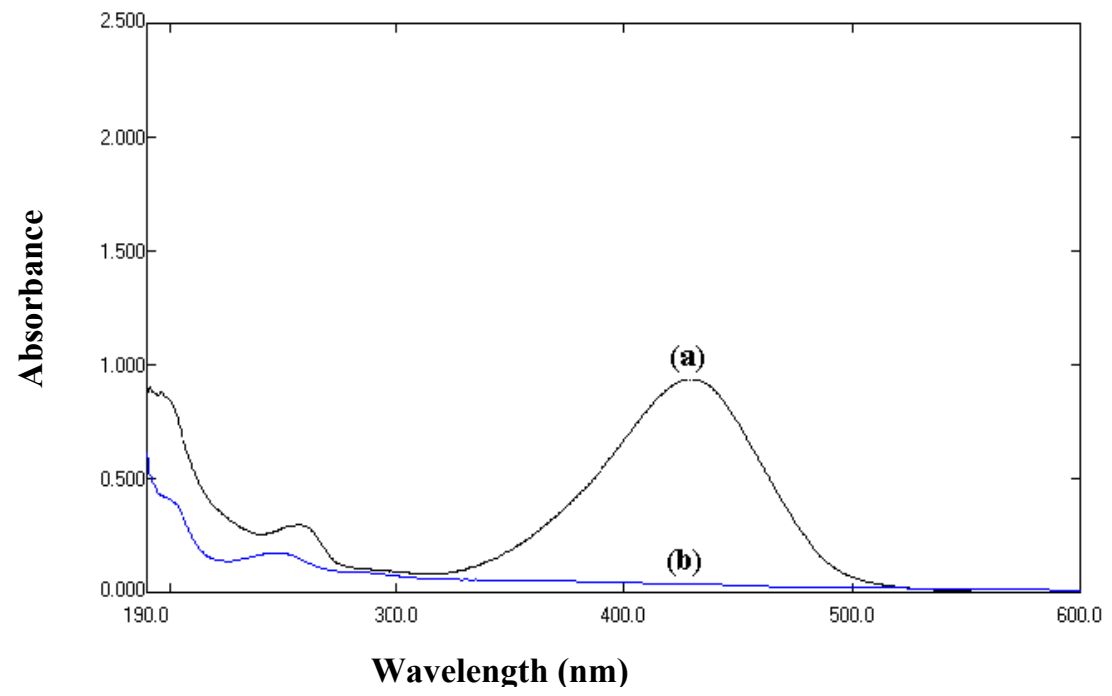

Figure 6: Absorbance as a function of wavelength for the Orange 6 pollutant: a) peak at $430 \mathrm{~nm}$, before contact with iron particles $(20$ $\mathrm{nm})$ and b) after treatment with iron nanoparticles for 30 minutes.

The UV-Vis absorbance spectra of the Orange 6 dye $(5 \mathrm{ppm}$ and $\mathrm{pH}=5.0)$ before and after the addition of the iron nanoparticles are presented in Figure 5. It can be seen that in the spectrum obtained after 30 minutes of contact the characteristic peak at $430 \mathrm{~nm}$ disappears completely, indicating the total degradation of the organic colorant originally present in the solution.

Considering that quartz is a mineral commonly present in the groundwater aquifers walls the adsorption of the organic dye on the quartz surface was also studied. In Figure 6, the values of zeta potential of quartz obtained as a function of the Orange 6 dye concentration at $\mathrm{pH}=6.0$, after 20 hours of contact time are presented. The zeta potential decreases as the Orange 6 concentration increases up to $40 \mathrm{ppm}$. The sharp decrease in the negative value of the zeta potential is indicative of the adsorption of the organic compound on the quartz surface.

\section{Discussion}

The change in color observed during the degradation process is certainly related to the breaking of the $-\mathrm{N}=\mathrm{N}$ - groups by the electrons liberated by the zero-valent iron oxidation. The absorbance spectra observed in Figure 5 show that the iron nanoparticles were able to degrade the organic dye in a very short period of time. The main products of this process are probably 1,2 dihydroxynaftalene and benzene, according to the mechanism proposed by Roy et al. [11].

The increase in the negative values of zeta potential observed when quartz particles were contacted with the dye solution suggests that adsorption of the anionic dye is taking place on the negative surface of quartz. Considering the anionic character of the organic pollutant, in the absence of favoring electrostatic 


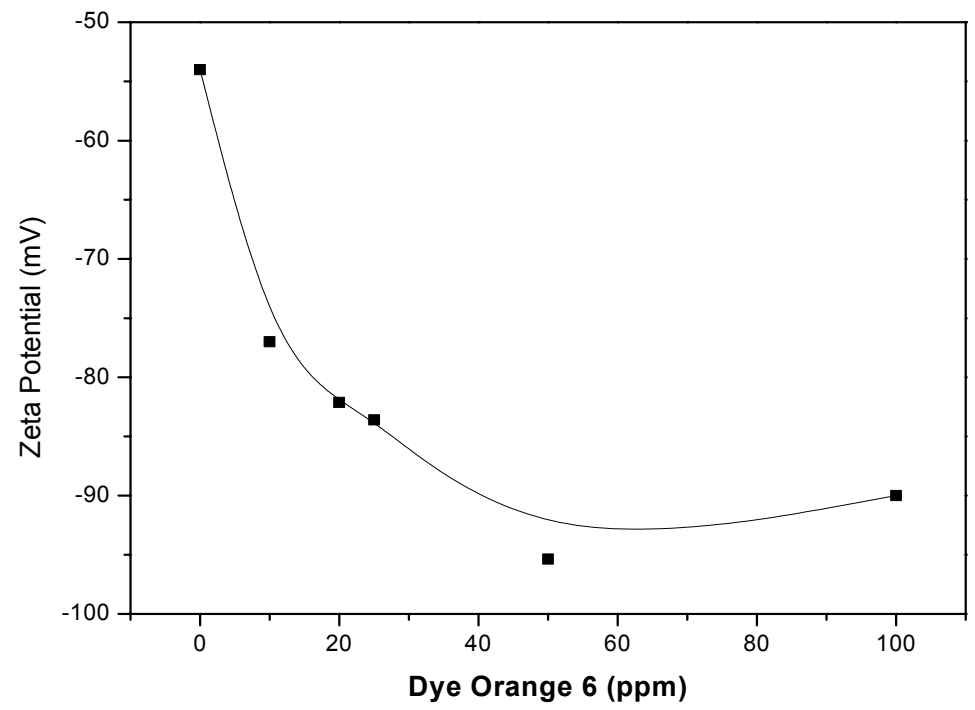

Figure 7: Zeta potential of quartz as a function of the Orange 6 concentration after 20 hours conditioning at $\mathrm{pH}=6.0$.

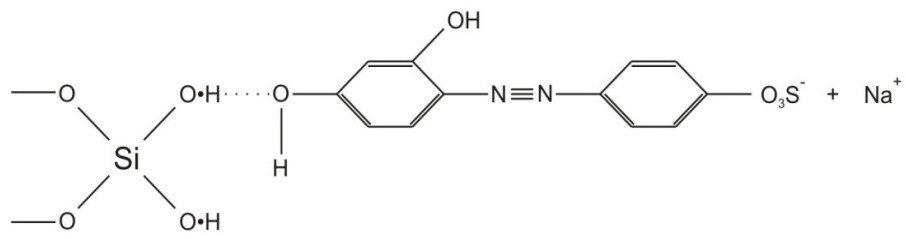

Figure 8: $\quad$ Proposed mechanism for the adsorption of the Orange 6 pollutant on the quartz surface.

forces the adsorption mechanism could be explained by hydrogen bonding between the $\mathrm{OH}$ group in the organic molecule and the silanol groups $(-\mathrm{SiOH})$ on the quartz surface. This proposed mechanism is presented in Figure 7.

The adsorption of the organic pollutant on the aquifer walls should thus be taken into consideration because it may delay the degradation process. On the other hand, there is also a possibility that the 1,2 didydroxynaftalene resultant of the degradation process could adsorb on the aquifer walls as well.

\section{Conclusions}

The utilization of zero-valent iron in the remediation of water pollution by the Orange 6 dye was shown to be a promising solution, mainly when iron nanoparticles are used. They present the advantage of requiring smaller contact time and also a more efficient transport in underground aquifers porous media. 
As far as the possibilities of application of this system are concerned it was verified by zeta potential measurements that the Orange 6 dye adsorbs strongly on the surface of quartz, generally one of the main constituents of the aquifers walls. This fact should be taken into consideration in industrial environmental application of the process.

The results obtained in the present work confirm that the use of zero-valent iron is a promising process in the remediation of groundwater polluted by organic compounds, particularly in the case of nitro aromatic compounds which, normally, are not so efficiently treated by traditional processes.

\section{Acknowledgements}

Financial support for this work from CAPES, Brazil, is gratefully acknowledged. Thanks are due to Thiago Moraes for conducting part of the experiments.

\section{References}

[1] Lien, H.L. \& Zhang, W.X., Nanoscale Iron Particles for Complete Reduction of Chlorinated Ethenes, Colloids and Surfaces A: Physicochemical and Engineering Aspects, 191, pp. 97-105, 2001.

[2] Liu, Y., L. Majetich, S.A., Tilton, R.D., Sholl, D.S. \& Lowry G.V., TCE Dechlorination Rates, Pathways, and Efficiency of Nanoscale Iron Particles with Different Properties, Environmental Science Technology, 39(5), 13381345, 2005.

[3] Gillham, R.W. \& O'Hannsenin, Enhanced Degradation of Halogenated Aliphatics by Zero-Valent Iron, Ground Water, 32 (6), pp. 958-967, 1994.

[4] Matheson L.J. \& Tratnyek, P.G., Reductive Dehalogenation of Chlorinated Methanes by Iron Metal, Environmental Science Technology, 28, pp. 20452053, 1994.

[5] Reynolds, G.W., Hoff, J.T. \& Guillham, R.W., Sampling Bias Caused by Materials used to Monitor Halocarbons in Groundwater, Environmental Science Technology, 24(1), pp. 135-142,1990.

[6] Wadley, S.L.S., Guillham, R.W. \& Gui, L, Remediation of DNAPL Source Sones with Granular Iron: Laboratory \& Field Tests, Ground Water, 43(1), pp.9-18, 2005.

[7] Elliot, D.W. \& Zhang, W.X., Field Assessment of Nanoscale Bimetallic Particles for Groundwater Treatment, Environmental Science Technology, 35, pp. 4922-4926, 2001.

[8] Deng, N., Luo, F., Wu, F., Xiao, M. \& Wu, X., Discoloration of aqueous reactive dye solutions in the $\mathrm{UV} / \mathrm{Fe}^{0}$ system, Water Research, 34(8), pp. 2408-2411, 2000.

[9] Sun, Y.P., Li, X.Q., Cao, J., Zhang, W.X., \& Wang, H.P., Characterization of Zero-Valent Iron Nanoparticles, Advances in Colloid and Interface Science, 120(1-3), pp. 47-56, 2006. 
[10] Agraval, A. \& Tratnyek, P.G., Reduction of Nitro Aromatic Compounds by Zero-Valent Iron Metal, Environmental Science and Technology, 30(1), pp. 153-160, 1996.

[11] Roy, G., Donato, P., Gorner, T. \& Barres, O., Study of Tropaeolin Degradation by Iron Proposition of a Reaction Mechanism, Water Research, 37(20), pp. 4954-4964, 2003. 